\title{
Classification of Sad Emotions and Depression Through Images Using Convolutional Neural Network $(\mathrm{CNN})$
}

\author{
Muhammad Fathur Prayuda ${ }^{1}$ \\ ${ }^{1}$ Program Studi Teknik Informatika, Fakultas Industri Kreatif dan Telematika, Universitas Trilogi, Jl. \\ Duren Tiga Timur No.30, RT.5, Kalibata, Kec. Pancoran, Kota Jakarta Selatan, Daerah Khusus Ibukota \\ Jakarta 12760 \\ e-mail: 1' faturprayuda@trilogi.ac.id
}

Submitted Date: December $21^{\text {st }}, 2020$

Revised Date: January $22^{\text {nd }}, 2021$
Reviewed Date: December $31^{\text {st }}, 2020$

Accepted Date: June $15^{\text {th }}, 2021$

\begin{abstract}
The human face has various functions, especially in expressing something. The expression shown has a unique shape so that it can recognize the atmosphere of the feeling that is being felt. The appearance of a feeling is usually caused by emotion. Research on the classification of emotions has been carried out using various methods. For this study, a Convolutional Neural Network (CNN) method was used which serves as a classifier for sad and depressive emotions. The CNN method has the advantage of preprocessing convolution so that it can extract a hidden feature in an image. The dataset used in this study came from the Facial expression dataset image folders (fer2013) where the dataset used for classification was taken with a ratio of $60 \%$ training and $40 \%$ validation with the results of the trained model of $60 \%$ total loss and $68 \%$ test accuracy.
\end{abstract}

Keywords: CNN; Depression; Deep Learning.

Abstrak

Raut wajah manusia memiliki berbagai macam fungsi khususnya dalam mengekspresikan sesuatu. Ekspresi yang ditunjukkan memiliki bentuk unik sehingga dapat dikenalinya suasana perasaan yang sedang dirasakan. Munculnya sebuah perasaan biasanya ditimbulkan oleh emosi. Penelitian tentang klasifikasi emosi sudah banyak dilakukan dengan berbagai macam metode. Untuk penelitian ini, digunakannya sebuah metode Convolutional Neural Network (CNN) yang berfungsi sebagai pengklasifikasi emosi sedih dan depresi. Metode CNN memiliki keunggulan dalam melakukan preprocessing pada konvolusi sehingga dapat mengekstrak sebuah ciri yang tersembunyi pada sebuah citra. Dataset yang digunakan dalam penelitian ini berasal dari Facial expression dataset image folders (fer2013) dimana dataset yang digunakan untuk klasifikasi diambil dengan ratio $60 \%$ training dan $40 \%$ validasi dengan hasil model yang dilatih sebesar $60 \%$ total loss dan $68 \%$ test accuracy.

Kata Kunci: CNN; Depresi; Deep Learning.

\section{Pendahuluan}

Sebanyak $11,6 \%$ populasi di Indonesia mengidap gangguan mental dan emosional dan sebagian besar yang dialami oleh pengidap gangguan mental dan emosional tidak mendapatkan pengobatan yang sama dengan penyakit lainnya sehingga mengakibatkan kegagalan dalam memberikan standar layanan kesehatan mental di Indonesia, hal tersebut membuat sistem kesehatan di Indonesia masih tertinggal dengan negara tetangganya di asia tenggara (Praharso, Pols, \& Tiliopoulos, 2020). Depresi merupakan salah satu penyakit gangguan mental yang serius dan biasa terjadi pada negara yang berpenghasilan rendah dan menengah (Brathwaite, et al., 2020).

Ekspresi wajah dapat menjadi sebuah komunikasi non-verbal yang dapat menyampaikan sebuah keadaan berdasarkan apa yang dialami oleh seseorang berdasarkan emosi yang dirasakannya, baik itu emosi positif maupun emosi negative dan ekspresi akan secara tidak sengaja muncul untuk 
menggambarkan suasana emosi yang dirasakannya (Prasetyawan \& 'Uyun, 2020). Pada dasarnya emosi memiliki empat karakteristik, yaitu: senang, sedih, marah, dan netral. Emosi depresi timbul berdasarkan emosi sedih yang berkelanjutan dalam jangka waktu yang lama. Emosi sedih yang berkelanjutan dapat menyebabkan berpikiran negatif sehingga menyebabkan sesuatu yang merugikan.

Penampakan wajah pada seorang yang mengalami depresi memiliki persamaan dengan tampak wajah yang sedang mengalami kesedihan. Hal tersebut membuat dugaan ketika meilhat wajah sedih menandakan bahwa emosi yang dirasakan juga sedih, raut wajah sedih juga dapat menyampaikan bahwa emosi yang dirasakan merupakan depresi. Gejala depresi pada setiap orang dapat berbeda-beda, pada umumnnya gejala pada depresi seperti: mengalami penurunan minat pada aktivitas sehari-hari, memiliki waktu tidur yang bermasalah (insomnia), merasa tidak dihargai, merasa bersalah terus-menerus, atau pun memiki rasa ingin mengakhiri hidup. Pengidap depresi bersifat lebih tertutup dan lebih sering menampakkan dirinya dengan wajah yang periang, tetapi beberapa pengidap juga menampilkan sisi depresi tersebut dengan cara melakukan sesuatu yang dapat membuat lingkungan sekitarnya menjadi kurang baik dan merugikan orang lain. Tantangan lain yang dialami pengidap depresi melibatkan stigmatisasi.

Berdasarkan Riset Kesehatan yang dilakukan oleh Kementrian Kesehatan Republik Indonesia (2018), terdapat 600-800 psikiater, dimana 1 psikiater melayani $300.000-400.000$ pasien. Berdasarkan informasi dari Ikatan Psikolog Indonesia (IPK), terdapat 1.143 psikolog yang menangani langsung di bidang kesehatan dan rumah sakit, jumlah psikolog di Indonesia sangat kurang berdasarkan standar dari Organisasi Kesehatan Dunia (WHO) yaitu 1 tenaga psikolog dapat melayani 30.000 pasien (Nurlita \& Nadiroh, 2019). Dengan citra, dapat membedakan keunikan antara raut wajah sedih yang memiliki emosi sedih dan raut wajah sedih yang memiliki emosi depresi, sehingga dapat meminimalisir emosi depresi dengan mengetahui raut wajah sedih.

Convolutional Neural Network merupakan sebuah metode Deep Learning yang banyak digunakan untuk mengidentifikasi sebuah citra dan dapat mengklasifikasikan sebuah kelas pada citra. Sehingga dengan adanya penelitian ini, diharapkan dapat lebih memperhatikan orang terdekat yang mengalami depresi dan mengurangi tingkat depresi di Indonesia.

\section{Penelitian Terkait}

Penelitian dengan judul Klasifikasi Emosi Berdasarkan Ciri Wajah Menggunakan Convolutional Neural Network meneliti mengenai bagaimana menguji kepuasan konsumen terhadap penerimaan produk pada suatu pasar. Agar dapat mengetahui lebih jauh mengenai perilaku konsumen dibuatnya penelitian untuk dapat megukur emosi konsumen karena dapat mempengaruhi perilaku konsumen. Metode yang digunakan yaitu Convolution Neural Network dengan jumlah data gambar sebanyak 327 buah dari 210 subjek yang diperoleh melalui Extended Cohn-Kanade Dataset (CK+). Hasil akurasi yang diperoleh sebesar $86,4 \%$ dengan rata rata akurasi 80,7\% (Yusuf, Wihandika, \& Dewi, 2020).

Penelitian dengan judul IMPLEMENTASI CONVOLUTIONAL NEURAL NETWORKS (CNN) UNTUK KLASIFIKASI EKSPRESI CITRA WAJAH PADA FER-2013 DATASET menjelaskan mengenai pengujian pada CNN terhadap gambar wajah yang memiliki emosi sedih dan senang menggunakan dataset FER2013 serta menggunakan Adamax Optimizer agar dapat menghasilkan performa yang terbaik dan menghasilkan akurasi sebesar $66 \%$ disbanding menggunakan optimizer Adam, N-Adam, dan SGD (Nugroho, Fenriana, \& Arijanto, 2020).

Penelitian tentang IMPLEMENTASI DEEP LEARNING MENGGUNAKAN CONVOLUTIONAL NEURAL NETWORK ( CNN ) PADA EKSPRESI MANUSIA merupakan aplikasi yang dapat mengklasifikasi emosi pada seseorang dengan menggunakan gambar (citra). Seluruh tahapan pada CNN disebut dengan preprocessing dan tahap klasifikasi. Pada tahap preprocessing dilakukannya tahap training yang menggunakan epoch dan batch size. Data set yang digunakan merupakan wajah senang, sedih, marah, takut, jijik, netral dan kaget. Dengan epoch 100 dan batch size 128, mendapatkan hasil akurasi training sebesar $90 \%$ dan validasi $65 \% .28$ gambar dari 35 gambar dapat diuji dengan dengan tingkat keakurasian 80\% (Alamsyah \& Pratama, 2020).

\section{Hasil dan Pembahasan}

\section{A. Convolutional Neural Network (CNN)}

Merupakan salah satu jenis metode pada Deep Learning yang dapat mengidentifikasi sebuah citra berdasarkan node-node atau kumpulan dari neuron yang memiliki kedalaman jaringan yang 
tinggi yang akan di filter (layer Konvolusi). Keunggulan CNN dibanding dengan metode Machine Learning lainnya dapat mempelajari modul Unsupervised sebagai fitur tanpa harus ditentukan terlebih dahulu. CNN biasa digunakan dalam menganalisa, mengenali dan mendeteksi sebuah citra yang memiliki dimensi vector yang tinggi sehingga melibatkan beberapa parameter dalam mencirikan jaringan (Septian, Saputra, \& Sambasri, 2020).

\section{B. Convolution Layer}

Merupakan bagian utama dalam memfilter sebuah citra yang terdapat kernel dan sub citra dan menghasilkan activation map. Pada umumnya, ukuran kernel adalah $3 \times 3$ dan pada sub citra, memiliki ukuran yang sama dengan kernel ketika operasi konvolusi dilakukan (Paliwang, Septian, Cahyanti, \& Swedia, 2020).

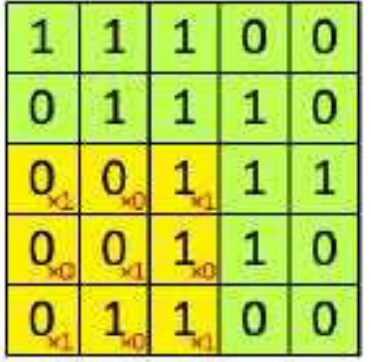

Image

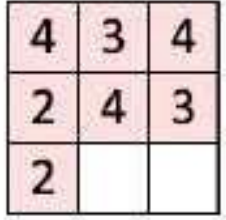

Convolved

Feature
Gambar. 1 Proses Convolution Layer.

\section{Pooling Layer}

Merupakan sebuah proses yang mengecilkan dimensi layer sebelumnya dengan menggunakan operasi downsampling pada dimensi yang memiliki lebar dan tinggi (spasial). Operasi yang dilakukan Pooling Layer tidak jauh berbeda dengan proses konvolusi. Pooling layer melakukan pergeseran yang akan ditentukan dengan jumlah stride untuk menggeser seluruh field activation map. Beberapa teknik pada Pooling Layer diantaranya: max pooling (mengambil nilai terbesar pada suatu window), average pooling (membuat nilai rata rata pada suatu window), dan sum pooling(menjumlahkan nilai dan memberikan hasil pada suatu window) (Arrofiqoh \& Harintaka, 2018).

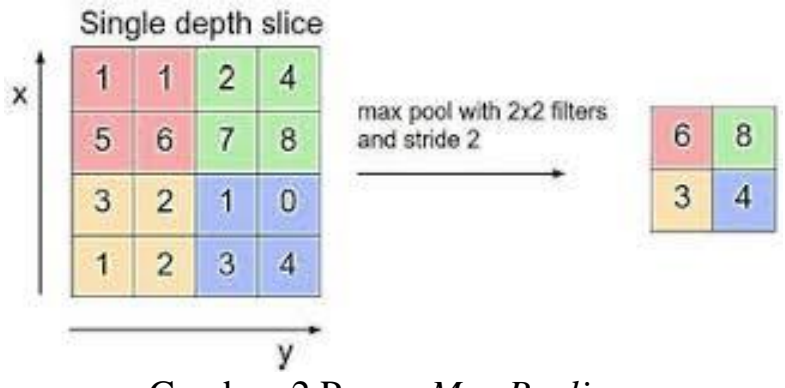

Gambar. 2 Proses Max Pooling.

\section{Fully Connected Layer}

Merupakan sebuah layer yang terdiri dari node-node. Untuk dapat diproses pada layer ini, activation map yang memiliki bentuk multidimensional array (matriks) diubah menjadi vector 1 dimensi (proses flattening) agar dapat diklasifikasikan dan juga menggunakan softmax (Syahputra \& Wibowo, 2020).

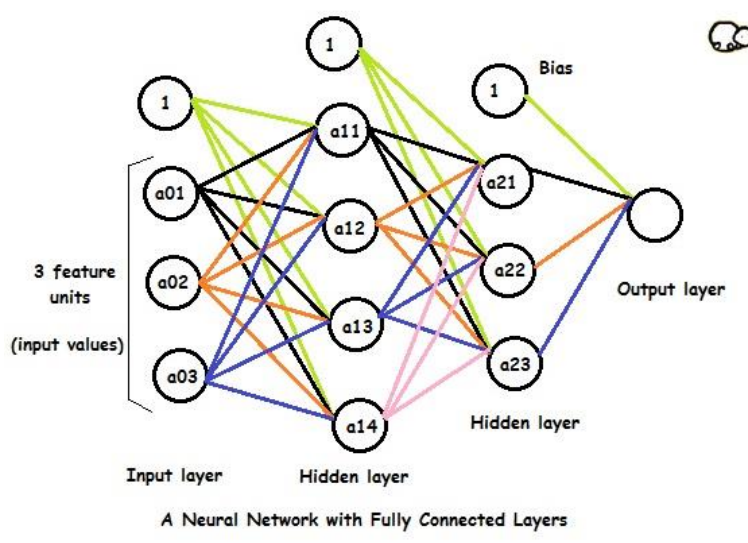

Gambar. 3 Proses Fully Connected Layer.

E. Tipe Penelitian

Penelitian ini dibuat untuk menerapkan sebuah permasalahan dengan metode yang digunakan. Penelitian ini menjelaskan bagaimana keunikan karakter dari objek yang diteliti dan akan disampaikan pada hasil penelitian.

\section{F. Data Penelitian}

Data penelitian menggunakan data gambar wajah yang memiliki emosi yang didapat dari website keggle.com dengan nama data Facial expression dataset image folders (fer2013). Data tersebut memiliki tingkat akurasi terbaik sebesar $68 \%$.

\section{G. Gambaran Umum Program}

Pada proses yang dilakukan, diawali dengan preprocessing data, dimana data disiapkan terlebih dahulu menjadi dataset yang nanti akan menjadi data train (training) dan data validasi dan 
diberikkannya setiap dataset dengan label untuk dapat digunakan diproses training. Lalu pada proses training, dilatihnya data dengan $\mathrm{CNN}$ untuk menghasilkan sebuah model yang nantinya model ini akan digunakan pada proses testing untuk dapat mengklasifikasikan data.

\section{Kesimpulan}

Pada penelitian ini, data yang digunakan berasal dari keggle.com dengan judul Facial expression dataset image folders (fer2013) dan menggunakan data yang berada di folder dengan nama folder 2 dan 4 . Total kedua data tersebut berjumlah 8927 gambar. Agar data gambar dapat diolah, kedua gambar tersebut dibagi menjadi 2 dataset, yaitu data training dan validasi. Pembagian dataset diambil dengan ratio $60 \%$ training dan $40 \%$ validasi. Setelah data set di siapkan, maka jumlah data menjadi 4830 gambar dataset sedih dan 4097 gambar dasaset depresi. Untuk data training sedih digunakan sebanyak 2898 gambar dan data validasi sedih digunakan sebanyak 1932 gambar. Untuk data training depresi digunakan sebanyak 2458 gambar dan untuk data validasi depresi digunakan sebanyak 1639 gambar.

Tabel 1. Total Data yang Digunakan

\begin{tabular}{|l|l|l|l|l|}
\hline & Training & validasi & Total & $\begin{array}{c}\text { Total } \\
\text { Keseluruhan }\end{array}$ \\
\hline $\begin{array}{l}\text { Data } \\
\text { Depresi }\end{array}$ & 2458 & 1639 & 4097 & 8927 \\
\hline $\begin{array}{l}\text { Data } \\
\text { Sedih }\end{array}$ & 2898 & 1932 & 4830 & 8927 \\
\hline
\end{tabular}

Setelah data set disiapkan, dilatihnya dataset agar dapat menjadil model yang dapat digunakan untuk mengklasifikasikan emosi.

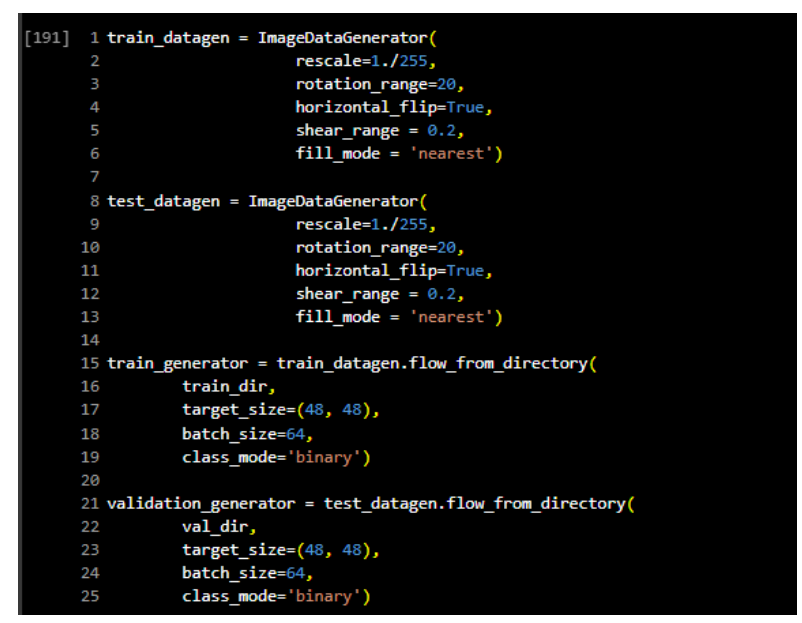

Gambar 4. Pelatihan data.
Pada gambar 4. menjelaskan proses pelatihan data pada setiap kelas terhadap data validasi dan training dimana fungsi imageDataGenerator() berfungsi untuk mengatur skala gambar yang dilatih sehingga dapat membuat fungsi flow_from_directory() dapat dilatih dengan ukuran gambar $48 \times 48$ pixel dan batch_size merupakan jumlah contoh gambar yang diberikan pada setiap jaringan.

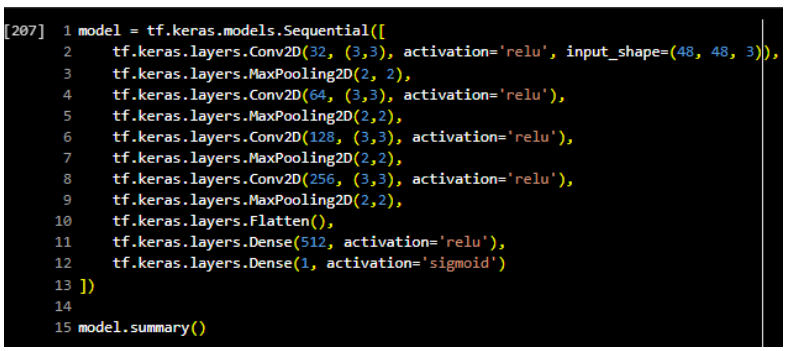

Gambar 5. CNN Arsitektur

Pada gambar 5. menjelaskan arsitektur CNN dimana fungsi layers.Conv2D merupakan konvolusi, relu merupakan fungsi yang bertanggung jawab menormalisasikan nilai yang dikirim melalui konvolusi pada konvolusi layer dan input shape merupakan bentuk dari inputan model dengan ukuran 48x48 pixel dan juga mengirimkan hidden layer pertama pada ke 3 channel. Fungsi Maxpooling2D merupakan fungsi untuk mengambil nilai terbesar dengan matriks $2 \times 2$. Fungsi layers.flatten berfungsi untuk merubah matrik menjadi vector 1 dimensi.sedangkan fungsi layers.dense merupakan fungsi yang menjadi fully connected, di mana menandakan keseluruhan node pada hidden layer.

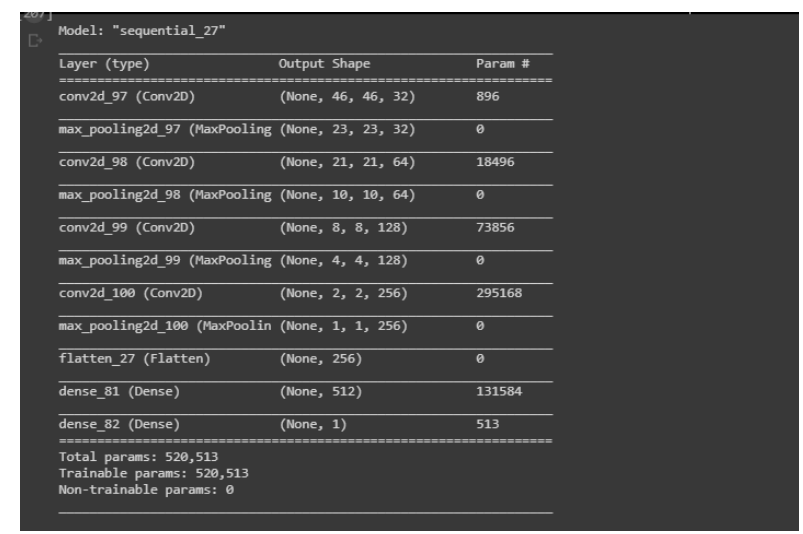

Gambar 6. Hasil dari Arsitektur CNN

Setelah data dilatih, didapatkannya model yang akan digunakan untuk dites. Agar model memiliki optimasi yang lebih akurat diambahkannya optimizer dengan tipe Adam. Adam optimizer berfungsi untuk mengoptimalkan 
data dengan memperbarui nilai weight yang terdapat pada network dengan cara iterative yang didapat dari data training.

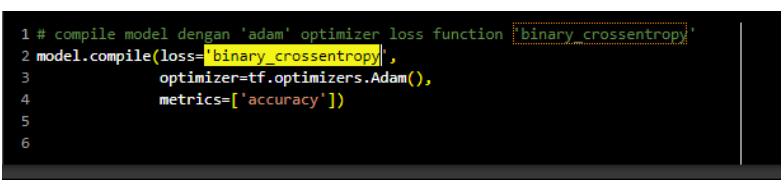

Gambar 7. Proses Adam Optimizer

Setelah model diberikan adam optimizer, dilatihnya model untuk proses kelasifikasi sesuai dengan yang diinput oleh user.

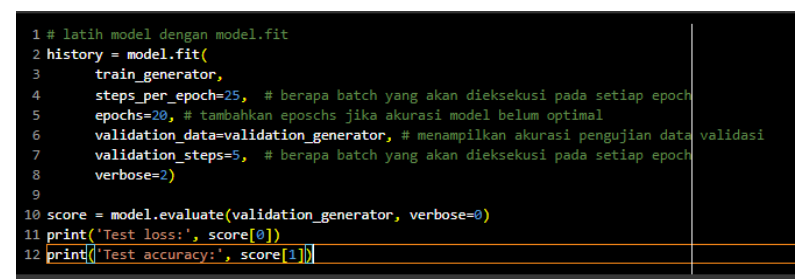

Gambar 8. Proses Melatih Model

Fungsi pada model.fit merupakan fungsi yang digunakan untuk melatih model dimana data yang digunakan dari data traning_generator dengan step per epoch 25 dengan jumlah epoch 20. Epoch merupakan dataset yang dikumpulkan pada data training. Untuk validasi_data dignakan dari folder validation_generator dengan jumlah batch per epoch (validation_step) $=5$.

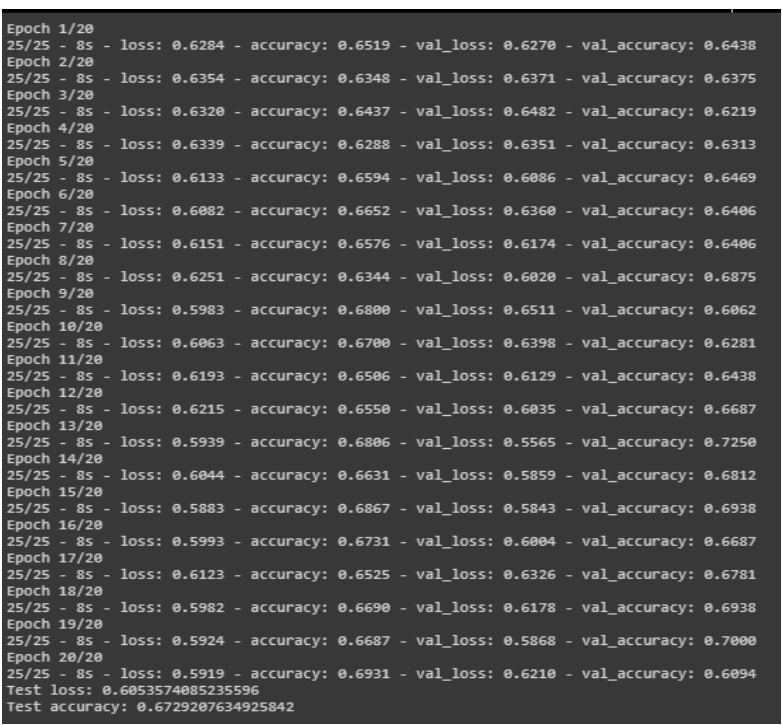

Gambar 9. Hasil Training Model

Pada gambar 9. Hasil yang dilakukan ketika melatih model didapat total loss sebesar $60 \%$ dan test accuracy sebesar $68 \%$. Sehinga pada grafik digambarkan pada gambar 10 .

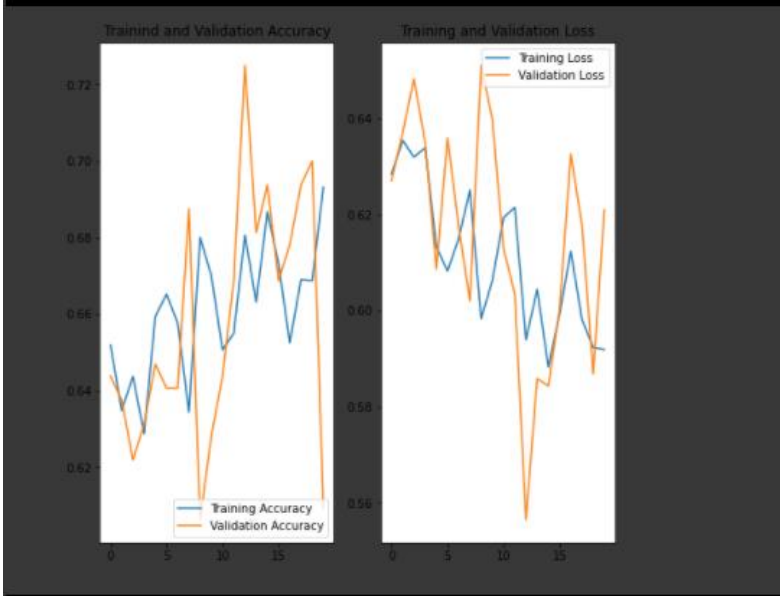

Gambar 10. Hasil Data Training Model Dalam Bentuk Grafik

Untuk menguji keakuratan model, diujinya gambar yang sudah disediakan untuk mengecek hasil yang sudah di lakukan oleh model training.

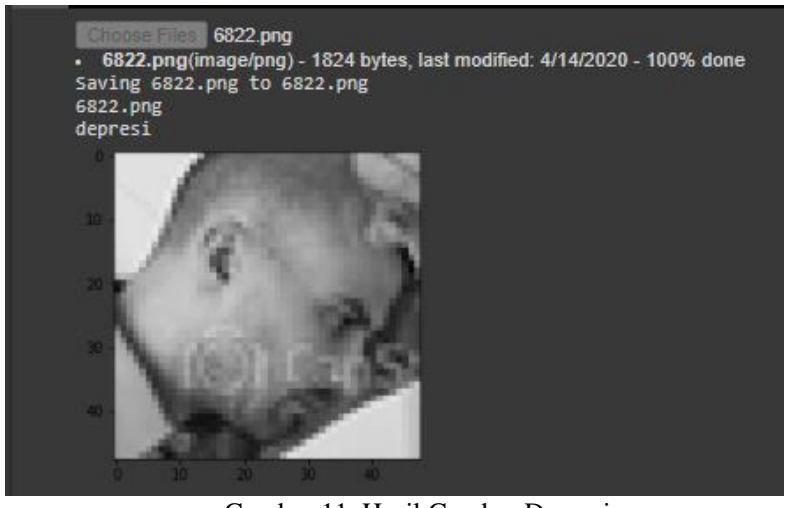

Gambar 11. Hasil Gambar Depresi

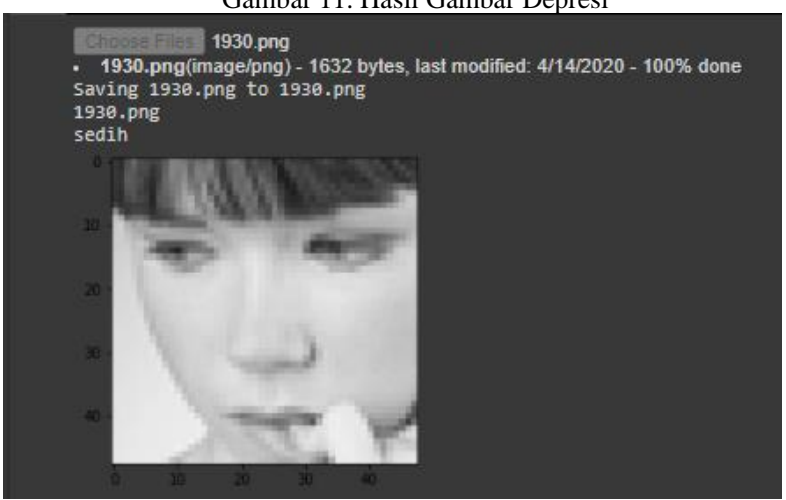

Gambar 12. Hasil Gambar Sedih.

\section{Saran}

Pada penelitian Klasifikasi Emosi Sedih Dan Depresi Melalui Gambar Menggunakan Convolutional Neural Network. Didapatnya total akurasi terbaik sebesar $68 \%$ dan dapat mengklasifikasikan gambar ekspresi wajah sedih dan depresi. Kekurangan dari penelitian ini 
penggunaan data yang menjadi dataset belum menggunakan gambar wajah asli atau memiliki mimic wajah yg menunjukan wajah sedih ataupun depresi. Diharapkan untuk penelitian selanjutnya dapat membuat hasil akurasi yang lebih tinggi dengan menggunakan datset wajah dengan mimik asli sedih ataupun depresi.

\section{Referensi}

Alamsyah, D., \& Pratama, D. (2020). Implementasi Convolutional Neural Networks (CNN) untuk Klasifikasi Ekspresi Citra Wajah pada FER-2013 Dataset. JurTI (Jurnal Teknologi Informasi), 4(2), 350-355.

Arrofiqoh, E. N., \& Harintaka. (2018). Implementasi Metode Convolutional Neural Network Untuk Klasifikasi Tanaman Pada Citra Resolusi Tinggi. Geomatika, 24(2), 61-68.

Brathwaite, R., Rocha, T. B.-M., Kieling, C., Kohrt, B. A., Mondelli, V., Adewuya, A. O., \& Fisher, H. L. (2020). Predicting the risk of future depression among school-attending adolescents in Nigeria using a model developed in Brazil. Psychiatry Research, 113511.

Nugroho, P. A., Fenriana, I., \& Arijanto, R. (2020). Implementasi Deep Learning Menggunakan Convolutional Neural Network (CNN) Pada Ekspresi Manusia. Algor, 2(1), 12-20.

Nurlita, R., \& Nadiroh. (2019). Tingkat Depresi di Kalangan Remaja akibat Faktor.
Paliwang, A. A., Septian, M. R., Cahyanti, M., \& Swedia, E. R. (2020). Klasifikasi Penyakit Tanaman Apel Dari Citra Daun Dengan Convolutional Neural Network. Sebatik, 24(2), 207-212.

Praharso, N. F., Pols, H., \& Tiliopoulos, N. (2020). Mental health literacy of Indonesian health practitioners and implications for mental health system development. Asian Journal of Psychiatry, 102168.

Prasetyawan, D., \& 'Uyun, S. (2020). Penentuan Emosi pada Video dengan Convolutional Neural Network. JISKA (Jurnal Informatika Sunan Kalijaga), 5(1), 23-35

Septian, R., Saputra, D. I., \& Sambasri, S. (2020). Klasifikasi Emosi Menggunakan. ProsidingSeminar Nasional Teknik Elektro UIN Sunan Gunung Djati Bandung, 53-62.

Syahputra, M. I., \& Wibowo, A. T. (2020). Klasifikasi Genus Tanaman Anggrek Berdasarkan Citra Kuntum Bunga Menggunakan Metode Convolutional Neural Network (Cnn). eProceedings of Engineering, 7(2)., 8015.

Yusuf, A., Wihandika, R. C., \& Dewi, C. (2020). Klasifikasi Emosi Berdasarkan Ciri Wajah Menggunakan Convolutional Neural Network. Jurnal Pengembangan Teknologi Informasi dan Ilmu Komputer e-ISSN, 2548, 964X. 